\title{
Evidence for a Phosphorylated Form of Calmodulin in Chicken Brain and Muscle
}

\author{
YVES D. PLANCKE AND ELIAS LAZARIDES* \\ Division of Biology, California Institute of Technology, Pasadena, California 91125
}

Received 14 February 1983/Accepted 31 May 1983

\begin{abstract}
Phosphocalmodulin (PCaM) was identified after analysis of calmodulin (CaM) preparations by two-dimensional gel electrophoresis by using a modified ampholyte system to resolve very acidic proteins. The analysis of CaM prepared by the conventional procedure based upon its heat resistance and acidity as well as the analysis of whole urea extracts from brain showed that PCaM was a major component in this tissue. PCaM was $1 \mathrm{pH}$ unit more acidic than $\mathrm{CaM}$, and its electrophoretic mobility, unlike $\mathrm{CaM}$, was not changed by either calcium or ethylene glycol-bis( $\beta$-aminoethyl ether)- $N, N$-tetraacetic acid. In urea extracts of brain prepared in buffers containing phosphate and sodium fluoride, PCaM was as prominent as $\mathrm{CaM}$; it was partially converted into $\mathrm{CaM}$ after elution from the gel and reelectrophoresis. Amino acid analysis of PCaM and CaM purified by twodimensional gel electrophoresis showed the same composition for the two proteins, including their trimethyllysine content. Incorporation of ${ }^{32} \mathrm{P}$ occurred exclusively into the acidic variant when brain slices were incubated with $\mathrm{H}_{3}{ }^{32} \mathrm{PO}_{4}$; amino acid analysis showed that the phosphate was bound to serine residues. $\mathrm{CaM}$ was found also to be phosphorylated in vitro by a phosphorylase kinase preparation from skeletal muscle.
\end{abstract}

After its discovery as a $\mathrm{Ca}^{2+}$-dependent activator of cyclic nucleotide phosphodiesterase by Cheung (5) and Kakiuchi and Yamasaki (20), a number of other $\mathrm{Ca}^{2+}$-dependent enzymatic regulations have been attributed to calmodulin (CaM). Indeed, a survey of the literature shows that a large number of cellular metabolic reactions are under the control of $\mathrm{CaM}$. In addition, $\mathrm{CaM}$ exhibits a nonenzymatic interaction with certain proteins such as a $\mathrm{Ca}^{2+}$-dependent interaction with the $\alpha$ subunit of spectrin in many erythroid and nonerythroid cells (for review see reference 24 ) as well as a strong $\mathrm{Ca}^{2+}$-insensitive interaction with certain enzymes such as phosphorylase kinase $(\mathrm{PhK})(10,23)$. The great versatility in the biological functions of $\mathrm{CaM}$ is combined with a highly conserved structure of this protein among species. The fact that $\mathrm{CaM}$ is almost perfectly conserved throughout evolution suggests that each of the four $\mathrm{Ca}^{2+}$-binding sites and other characteristic features of the molecule are very important in one or another of the roles of the protein (7). This is why the detailed investigation of conformational states and chemical modifications of CaM may yield a better understanding of the regulation of a whole set of intracellular CaM-dependent events, such as the $\mathrm{Ca}^{2+}$ - and $\mathrm{CaM}$-dependent phosphoryla- tion of many enzymes. However, to date, the molecular details of CaM-stimulated phosphorylation are still unknown. Part of the difficulty in studying in vitro every parameter of a reaction involving $\mathrm{CaM}$ is that $\mathrm{CaM}$ is a very small and very acidic molecule and is difficult to be analyzed itself by electrophoresis $(11,14,26)$. To investigate the potential in vivo chemical modification of $\mathrm{CaM}$, we have analyzed $\mathrm{CaM}$, either purified from brain by conventional biochemical techniques or from whole brain extracts, by using an isoelectric focusing system with a modified $\mathrm{pH}$ gradient that allows the resolution of very acidic polypeptides. We show here that, in brain, CaM exists in a phosphorylated and a nonphosphorylated form. Under conditions of electrophoresis in which $\mathrm{PO}_{4}{ }^{2-}$ hydrolysis is minimized, the phosphorylated form of $\mathrm{CaM}$ $(\mathrm{PCaM})$ is present in almost equivalent amounts to the nonphosphorylated form. PCaM is more acidic than $\mathrm{CaM}$, and its electrophoretic mobility is not affected by either $\mathrm{Ca}^{2+}$ or ethylene glycol-bis( $\beta$-aminoethyl ether)- $N, N$-tetraacetic acid (EGTA). In addition, we show that $\mathrm{CaM}$ is phosphorylated in vitro in the presence of [ $\gamma$ ${ }^{32} \mathrm{PJATP}$ as the $\delta$ subunit of PhK from skeletal muscle or when added exogenously to a PhK preparation from skeletal muscle. The results 
imply that PCaM may be a new way that CaM regulates its interaction with enzymes or structural proteins.

\section{MATERIALS AND METHODS}

Standard preparation of CaM. Five brains from 18day-old chicken embryos were homogenized, and $\mathrm{CaM}$ was prepared as previously described (4). A 250ml gradient from 200 to $600 \mathrm{mM} \mathrm{NaCl}$ was applied to the ion-exchange column: $50 \mathrm{ml}$ of packed DEAESephadex A-50 equilibrated in $50 \mathrm{mM}$ Tris ( $\mathrm{pH} 7.0$ )$200 \mathrm{mM} \mathrm{NaCl}$. CaM eluted at about $400 \mathrm{mM} \mathrm{NaCl}$ and was lyophilized, desalted through a G-25 column equilibrated in $50 \mathrm{mM}\left(\mathrm{NH}_{4}\right) \mathrm{HCO}_{3}$, and lyophilized again.

Isoelectric focusing. Two-dimensional isoelectric focusing and sodium dodecyl sulfate (SDS) gel electrophoresis was carried out by the method of O'Farrell (28) with a modified $\mathrm{pH}$ gradient. The ratios of Ampholines (LKB Instruments, Inc.) used was $2.4 \%$ of $\mathrm{pH}$ range 3.5 to 10 and $0.8 \%$ of $\mathrm{pH}$ range 2.5 to 4 . The current was always maintained under $0.25 \mathrm{~mA}$ per tube to avoid protein precipitation at the top of the gel owing to overheating. Detergent was omitted from the samples. The second dimension after isoelectric focusing was run in gels containing $17.5 \%$ acrylamide and $0.074 \% N, N^{\prime}$-methylenebisacrylamide.

Urea extraction of brain. Ultrapure urea was purchased from Schwarz/Mann. A given weight of brain was mixed with the same weight of urea and then with $1 / 5$ this weight of the following buffer: $250 \mathrm{mM}$ Tris$100 \mathrm{mM}$ EGTA (pH 7.0)-100 mM $\beta$-mercaptoethanol$1 \mathrm{M} \mathrm{NaCl}$. Alternatively, the brain was mixed with the same amount of $200 \mathrm{mM}$ sodium pyrophosphate-200 mM EGTA-15 mM NaF-10 mM dithiothreitol-6 M urea at an approximate $\mathrm{pH}$ of 4.8 . The final concentration of urea was $7.2 \mathrm{M}$ with the first buffer and $3 \mathrm{M}$ with the second one.

Removal of SDS by ion-pair extraction. After twodimensional polyacrylamide gel electrophoresis (PAGE) and staining, the protein spot was cut and eluted by homogenization with a Teflon pestle in 50 $\mathrm{mM}\left(\mathrm{NH}_{4}\right) \mathrm{HCO}_{3}$ and then further mixed, washed, and centrifuged several times in the same buffer. Finally, the extract was lyophilized. Alternatively, the gel slices were subject to electroelution with several changes of $50 \mathrm{mM}\left(\mathrm{NH}_{4}\right) \mathrm{HCO}_{3}$, and the extract was lyophilized. SDS and Coomassie blue were removed from the protein by the procedure of Henderson et al. (16) with slight modifications. Since CaM is stable to acid treatment (23), difficulties have been encountered in its precipitation and its recovery; for this reason, SDS and Coomassie blue were removed by the addition to the protein solution of an extraction mixture consisting of acetone-triethylamine-acetic acid-water (17:1:1:1), and the mixture was cooled in an ethanolcarbonic ice bath. At a lower temperature than that used in the procedure of Henderson et al. (16), an aqueous phase containing $\mathrm{CaM}$ stuck against the wall of the tube. The organic phase was poured off.

PhK. (i) Preparation of a crude extract. The procedure for the preparation of $\mathrm{PhK}$ was derived from Cohen (9) and Pocinwong et al. (30). A 500-g amount of chicken breast and leg muscle was minced and stirred in 2 liters of $10 \mathrm{mM}$ sodium pyrophosphate adjusted to $\mathrm{pH} 9.0$ with acetic acid, containing $5 \mathrm{mM}$ magnesium acetate and $0.2 \mathrm{mM}$ phenylmethylsulfonyl fluoride. After a 60 -min centrifugation at $20,000 \times \mathrm{g}$, the supernatant was added to an equal volume of neutralized $3 \mathrm{M}$ ammonium sulfate and stirred overnight at $4^{\circ} \mathrm{C}$. The precipitate was collected after a 60 min centrifugation at $20,000 \times g$, dissolved in the homogenization buffer, and added to $600 \mathrm{ml}$ of DE52 cellulose (Whatman, Inc.) equilibrated in the same buffer. The slurry was stirred and centrifuged for 15 min at $1,000 \times g$ to pellet the resin. The resin was washed twice with the homogenization buffer and poured into a 4-cm-diameter column. An $\mathrm{NaCl}$ gradient from 0 to $0.5 \mathrm{M} \mathrm{NaCl}$ in $0.1 \mathrm{M}$ sodium glycerophosphate-2 mM EDTA ( $\mathrm{pH} 7.0)$ was started once no more protein was eluted as monitored by transmission at 254 $\mathrm{nm}$. The fraction volume was $7 \mathrm{ml}$, and the volume of the gradient was $500 \mathrm{ml}$. Elution was continued with $0.5 \mathrm{M} \mathrm{NaCl}$ buffer until no more protein was eluted. Fractions were assayed for $\mathrm{PhK}$ activity with phosphorylase $b$ (Sigma Chemical Co.) as a substrate (see below).

(ii) PhK assay. The buffer was derived from Kilimann and Heilmeyer (21): $1.5 \mathrm{mM}$ sodium glycerophosphate- $50 \mathrm{mM}$ magnesium chloride- $0.2 \mathrm{mM}$ calcium chloride ( $\mathrm{pH}$ adjusted to 9.0 with $\mathrm{HCl}$ ). Solutions of phosphorylase $b(15 \mathrm{mg} / \mathrm{ml})$ and of $\mathrm{CaM}$ $(10 \mathrm{mg} / \mathrm{ml})$ were made in this buffer. $\left[\gamma^{32}{ }^{32}\right.$ P]ATP $(1$ $\mathrm{mCi}$, carrier free; New England Nuclear Corp.) was dissolved in $10 \mathrm{ml}$ of $20 \mathrm{mM}$ cold ATP in the PhK assay buffer. Routinely, $50 \mu \mathrm{l}$ of PhK crude extract was added to $10 \mu \mathrm{l}$ of either phosphorylase $b$ or $\mathrm{CaM}$ solution and $50 \mu \mathrm{l}$ of ATP solution. The reaction was stopped by a $10 \times$ sample buffer (10\% SDS, $1.25 \mathrm{M}$ Tris [pH 6.8], 10\% $\beta$-mercaptoethanol, $10 \mathrm{mM}$ EDTA, and $0.05 \%$ bromophenol blue) and placed in a boiling water bath for $5 \mathrm{~min}$. After slab gel electrophoresis, the gels were dried and exposed for autoradiography for $18 \mathrm{~h}$ on Kodak XR-A film and du Pont Cronex Lightning-Plus intensifying screens. The radioactive bands of either phosphorylase $b$ or $\mathrm{CaM}$ were then cut out and counted by liquid scintillation counting in Aquasol II.

${ }^{32} \mathrm{PO}_{4}^{2-}$ incorporation in proteins from whole brain. Five chicken embryo brains (10 days old) were incubated at $37^{\circ} \mathrm{C}$ in minimal essential medium without phosphate for $3 \mathrm{~h}$. After $1 \mathrm{~h}$, the medium was changed, and $1 \mathrm{mCi}$ of $\mathrm{H}_{3}{ }^{32} \mathrm{PO}_{4}$ (carrier free; New England Nuclear Corp.) was added. The incubation was then continued for $10 \mathrm{~h}$. The brains were pelleted and submitted to Tris-urea-EGTA extraction as above before two-dimensional gel analysis. After Coomassie blue staining, the gels were dried and exposed for 1 week with intensifying screens.

Analysis for TML. After two-dimensional gel analysis of brains extracted in urea-EGTA, the main CaM spot $(\delta)$ and the acidic spot $\left(\delta^{\prime}\right)$ were electroeluted, submitted to ion-pair extraction (16), and analyzed for trimethyllysine (TML) content, first by thin-layer chromatography in two different solvent systems (22, 29) and second, with a Durrum amino acid autoanalyzer. The TML standard was a gift from Steven Clark, University of California, Los Angeles. For phosphoamino acid determination, the radioactively labeled $\left(\delta^{\prime}\right)$ variant was hydrolyzed after extraction in $5.6 \mathrm{~N} \mathrm{HCl}$ for $2 \mathrm{~h}$ and analyzed (as in reference 27). 


\section{RESULTS}

Analysis of CaM from the standard purification procedure. $\mathrm{CaM}$, purified from brain by the conventional procedure involving osmotic shock, heating, and ion-exchange chromatography, exhibits only one band after one-dimensional electrophoretic analysis in the presence of SDS (not shown). However, two-dimensional isoelectric focusing and SDS gel analysis of the same fractions shows a heterogeneity of the preparation (Fig. 1A). CaM is now resolved into one main variant as well as a more acidic variant as judged by Coomassie blue staining (Fig. 1A). Most often, all these acidic variants are not detectable, in particular, when the $\mathrm{pH}$ range of the acidic end of the first (isoelectric focusing) dimension is not expanded to resolve proteins
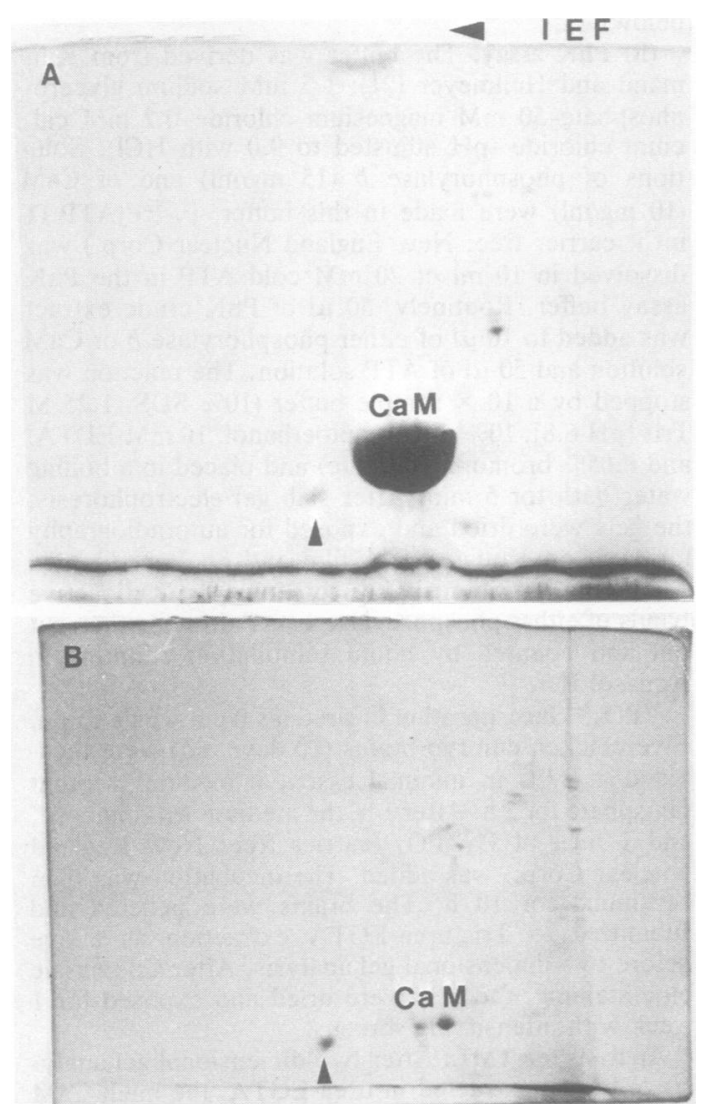

FIG. 1. Two-dimensional gel analysis of CaM. (A) CaM obtained from brain by a conventional method based on its heat resistance and its acidity. (B) Analysis of a direct urea extract of brain in the same system. The extraction was done in urea-phosphate-EGTA buffer with sodium fluoride as a phosphatase inhibitor. An acidic spot can be observed (arrow). The pI of the spots are 4.0 \pm .0 .2 for the main one $(\mathrm{CaM})$ and $3.0 \pm$ 0.2 for the minor one (arrow). with an isoelectric point more acidic than that of $\mathrm{CaM}$. Furthermore, since CaM may be distributed into a $\mathrm{Ca}^{2+}$-bound and a $\mathrm{Ca}^{2+}$-free form, substantial quantities of this protein need to be electrophoresed before the more acidic variants become detectable.

Analysis of CaM from urea extracts. Even though in the conventional procedure for the purification of $\mathrm{CaM}$, osmotic shock of the brain results in the release of this protein, substantial amounts of $\mathrm{CaM}$ still remain in the insoluble brain material after this treatment. If the osmotic shock-insoluble material is extracted with a urea- and EGTA-containing buffer and the extract is subsequently analyzed by two-dimensional isoelectric focusing and SDS-PAGE, a prominent polypeptide which corresponds to $\mathrm{CaM}$ is revealed. Coelectrophoresis of the osmotic shock-soluble and -insoluble forms of $\mathrm{CaM}$ shows that they share indistinguishable electrophoretic mobilities and isoelectric points after two-dimensional isoelectric focusing and SDSPAGE (data not shown). The intensity of the CaM spot is enhanced when the extracts are prepared in the presence of EGTA presumably owing to the conversion of all of the $\mathrm{CaM}$ to the $\mathrm{Ca}^{2+}$-free form.

Direct extraction of whole brain with a ureaEGTA-containing buffer results in the solubilization of higher quantities of CaM. Analysis of such whole brain urea-EGTA extracts by twodimensional isoelectric focusing and SDS-PAGE reveals the presence of a predominant polypeptide with an electrophoretic mobility in the second dimension similar to that of $\mathrm{CaM}$ but whose isoelectric point is ca. $1 \mathrm{pH}$ unit more acidic than the main $\mathrm{CaM}$ variant (referred to as $\delta^{\prime}$; Fig. 1B). Several gels from the first dimension were cut in slices to determine the $\mathrm{pH}$ of the gradient. The main $\mathrm{CaM}$ variant (referred to as $\delta$ ) was found to have a pI of $4.0 \pm 0.2$, whereas the more acidic variant $\left(\delta^{\prime}\right)$ had a pI of $3.0 \pm 0.2$. To estimate the concentration of the $\delta^{\prime}$ variant of $\mathrm{CaM}$ in brain, we calculated its concentration by amino acid analysis after elution from electropherograms of whole brain urea-EGTA extracts identical to that shown in Fig. 2A. Given the fact that $0.2 \mathrm{~g}$ of brain protein extract was applied per gel as in Fig. 2A and using $0.5 \mathrm{nM}$ valine as an internal standard in amino acid analysis, we calculated that there is $0.2 \times 10^{-5} \mathrm{M}$ of $\mathrm{CaM}$ in the $\delta^{\prime}$ variant and $0.6 \times 10^{-5}$ to $0.8 \times 10^{-5} \mathrm{M}$ in the $\delta$ variant. This value is to be correlated with the reported concentration of $\mathrm{CaM}\left(10^{-5} \mathrm{M}\right)$ in brain (23). Therefore, we can conclude that most of the CaM in brain is solubilized and recovered under the conditions of urea extraction used here. The recovery of the $\delta^{\prime}$ variant is low compared with the $\delta$ variant following the conventional technique for the purification of $\mathrm{CaM}$ 
(Fig. 1A); however, it is greatly improved if $\mathrm{CaM}$ is purified in buffers containing phosphate and $\mathrm{NaF}$, both of which inhibit protein phosphatase activity (Fig. 1B; see below).

One of the most striking characteristics of $\mathrm{CaM}$ is its ability to retain biological activity after exposure to protein denaturants, such as heat and urea, and to bind $\mathrm{Ca}^{2+}$ after exposure to SDS at $100^{\circ} \mathrm{C}(3,6,23)$. Upon addition of $\mathrm{Ca}^{2+}$, four Coomassie blue spots are resolved in urea extracts of whole brain in the position of $\mathrm{CaM}$. These $\mathrm{CaM}$ variants share the same isoelectric point of $4.0 \pm 0.2$, but they exhibit an increasing electrophoretic mobility (Fig. 2B). This pattern is in agreement with previous work showing that the interaction of $\mathrm{Ca}^{2+}$ with $\mathrm{CaM}$ apparently occurs in discrete steps (23). Upon $\mathrm{Ca}^{2+}$ binding, CaM undergoes a large conformational change accompanied by a 5 to $10 \%$ increase in its $\alpha$ helical content as determined by circular dichroism and optical rotary dispersion (23). The acidic variant $\left(\delta^{\prime}\right)$ has the electrophoretic mobility of $\mathrm{Ca}^{2+} \mathrm{CaM}$, but only one spot is seen by two-dimensional electrophoresis (Fig. 2). This variant appears to be insensitive to $\mathrm{Ca}^{2+}$, unlike the main $\mathrm{CaM}$ spot $(\delta)$, since its electrophoretic mobility is not altered when $\mathrm{Ca}^{2+}$ is chelated (see Fig. 1B). The extraction in Fig. 1 and 2 has been achieved first with EGTA. $\mathrm{CaCl}_{2}$ was only added to the sample before isoelectric focusing. Thus, we are not observing the $\mathrm{Ca}^{2+}$ effect on protein extraction but rather its effect on the electrophoretic mobility of proteins.

Conversion of PCaM into CaM. Different preparations of $\mathrm{CaM}$ were analyzed for the presence of the $\delta^{\prime}$ spot and the effect of $\mathrm{Ca}^{2+}$ on its electrophoretic mobility. Although a minor component, it was also found in the conventional preparation of CaM (Fig. 1A). After extraction of the protein from the gel slices as in Fig. $2 \mathrm{~A}$ and reelectrophoresis, the $\delta^{\prime}$ variant showed a partial transformation into the $\delta$ variant with the typical pattern of the incomplete saturation in $\mathrm{Ca}^{2+}$ (Fig. 3). When the urea extraction of the brain was performed in phosphate buffer with $\mathrm{NaF}$, the Coomassie blue intensities of the two spots were almost identical (Fig. 1B). These experiments suggest that the $\delta^{\prime}$ variant is phosphorylated. The dephosphorylation of $\mathrm{CaM}$ appears to occur rapidly as seen in Fig. 3 with the $\left(\mathrm{NH}_{4}\right) \mathrm{HCO}_{3}$ alkaline medium used to extract the protein, which destabilizes phosphoester bonds. This dephosphorylation process is difficult to quantify.

Presence of TML in the CaM variants. Elution of the protein from the gel as shown in Fig. 2A and subsequent analysis for the presence of TML by thin-layer chromatography showed the same pattern for the two variants $\left(\delta\right.$ and $\left.\delta^{\prime}\right)$ in

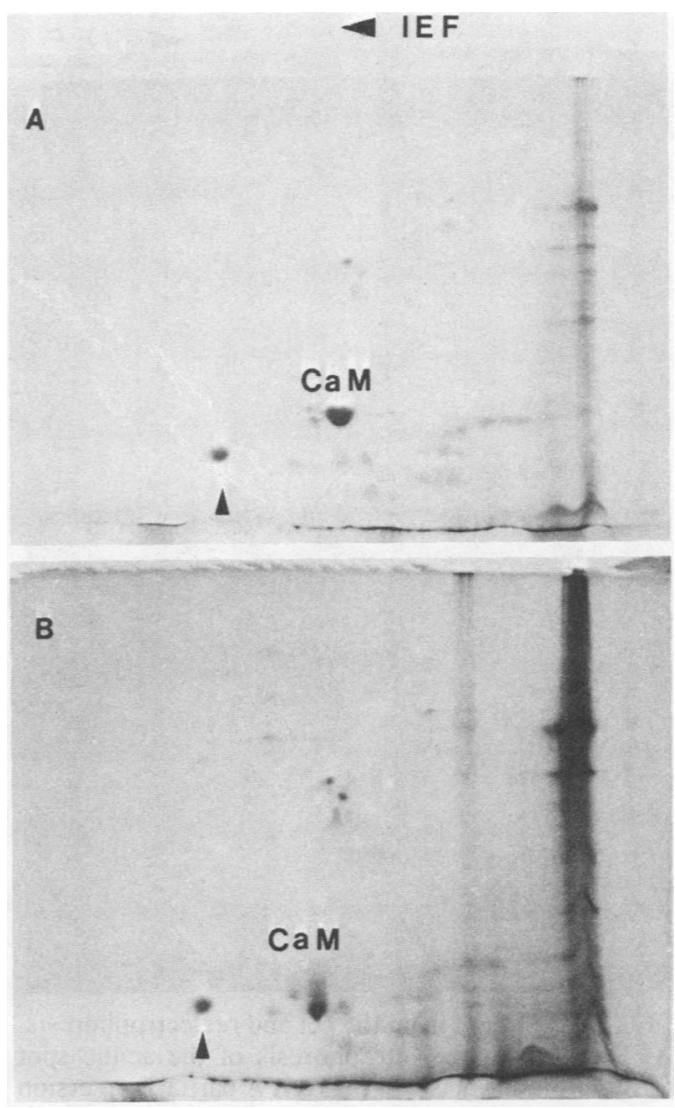

FIG. 2. Enhancement of the electrophoretic mobility of $\mathrm{CaM}$ by calcium. (A) Whole brain was extracted with a Tris-urea-EGTA buffer. When compared with Fig. 1B, CaM extracted in Tris buffer gives less of the acidic variant than the one extracted in phosphate buffer with $\mathrm{NaF}$. (B) $\mathrm{CaCl}_{2}$ was added in an equimolar concentration to EGTA to the sample immediately before isoelectric focusing. The electrophoretic mobility of the acidic spot (arrow) is not changed by $\mathrm{Ca}^{2+}$.

two different solvent systems $(22,29$; data not shown). Similarly, amino acid analysis showed the same overall amino acid composition characteristic of $\mathrm{CaM}$ for both variants (data not shown) and more characteristically, the presence of TML in both of them (Fig. 4). We can thus conclude that the $\delta^{\prime}$ variant is indeed a variant of CaM.

Phosphorylation of CaM in vivo. To more definitely establish that the $\delta^{\prime}$ variant of $\mathrm{CaM}$ was phosphorylated, we incubated brain slices with $\mathrm{H}_{3}{ }^{32} \mathrm{PO}_{4}$; this led to the incorporation of ${ }^{32} \mathrm{P}$ exclusively in the very acidic $\delta^{\prime}$ spot as revealed by a comparison of the Coomassie blue-stained two-dimensional gel and the corresponding autoradiogram (Fig. 5). Elution of the $\delta^{\prime}$ variant from the gel and analysis for the phosphorylated amino acid with the same technique as in reference 27 revealed only one spot corresponding to 


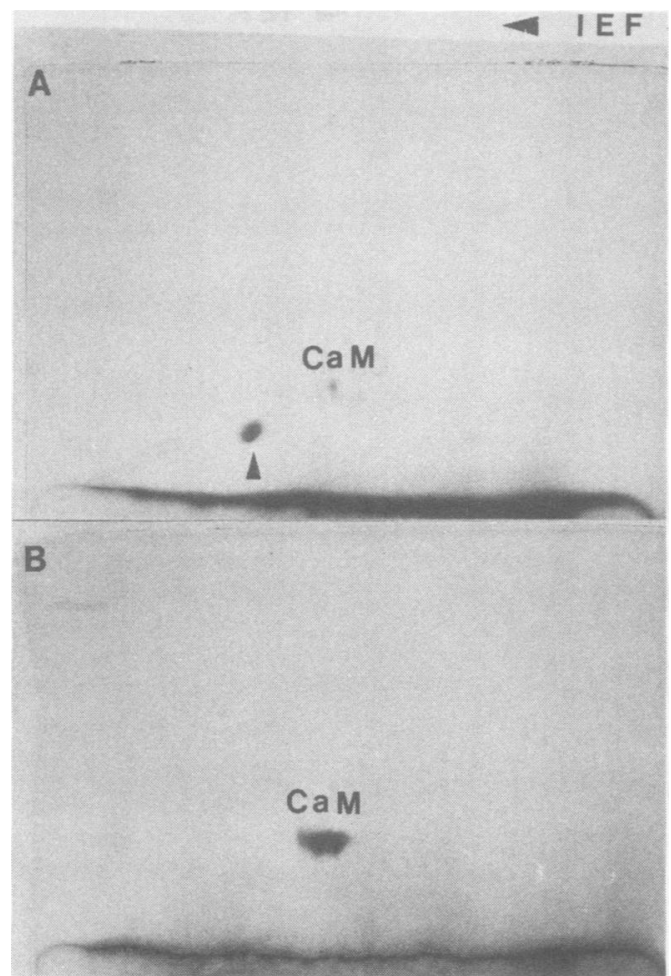

FIG. 3. Elution from the gel and reelectrophoresis. (A) Elution and reelectrophoresis of the acidic spot (arrow) from the gel as in Fig. 2A. A partial conversion into the main $\mathrm{CaM}$ spot is observed. (B) Same experiment with the main CaM spot.

phosphoserine (data not shown). The apparent lability of the phospho bond (see Fig. 3) makes a quantitative estimate of the extent of PCaM phosphorylation difficult.

Phosphorylation of $\mathrm{CaM}$ by $\mathrm{PhK}$ in vitro. Besides brain, muscle was analyzed for the presence of a phosphorylated form of CaM. Since $\mathrm{CaM}$ is the $\delta$ subunit of $\mathrm{PhK}$ (11) and binds strongly to the enzyme in the absence of $\mathrm{Ca}^{2+}$ (23), we partially purified $\mathrm{PhK}$ from muscle and examined the ability of CaM to be phosphorylated in vitro. A crude preparation of $\mathrm{PhK}$ was obtained from chicken muscle and assayed with phosphorylase $b$ as a substrate. In the absence of phosphorylase $b$, incubation with $\left[\gamma^{-32} \mathrm{P}\right] \mathrm{ATP}$ showed incorporation of radioactivity in a band corresponding to the Coomassie blue band of the $\delta$ subunit of $\mathrm{PhK}$ after analysis by one-dimensional PAGE (data not shown). To further enhance this labeling, exogenous CaM (purified as described in Fig. 1A) was used in the assay as a substrate. Phosphorylation of exogenous $\mathrm{CaM}$ by $\mathrm{PhK}$ increased linearly with increasing concentrations of CaM (Fig. 6). PhK assays were run under the same conditions with either phosphorylase $b$ or $\mathrm{CaM}$ as a substrate. After gel electrophoresis, the bands were cut out and counted by liquid scintillation. We observed that the amount of $\mathrm{P}_{\mathrm{i}}$ transferred to $\mathrm{CaM}$ was half the amount transferred to phosphorylase $b$ for the same weight of each protein (data not shown). Under these conditions, we found that 1 of 100 mol of exogenously added CaM was labeled with ${ }^{32} \mathrm{P}$. It would have been interesting to check for the presence of $\mathrm{PCaM}$ in the native $\mathrm{PhK}$ preparation by two-dimensional PAGE. Unfortunately, SDS is required to dissociate the individual polypeptides of $\mathrm{PhK}(17,18)$, and thus, the $\mathrm{pH}$ gradient cannot be standardized with the values of the previous experiments. The phosphorylation of $\mathrm{CaM}$ as the $\delta$ subunit of $\mathrm{PhK}$, a tetrameric enzyme with four chains $(\alpha \beta \gamma \delta)$ in the structure $(\alpha \beta \gamma \delta)_{4}$, has not been described until now, although the $\alpha$ and $\beta$ subunits are known to be phosphorylated by a cAMP-dependent kinase $(10,19)$. Our CaM phosphorylation experiments were carried out in the optimum ionic conditions for autophosphorylation of $\mathrm{PhK}$ as defined by Kilimann and Heilmeyer (21), who discuss the possibility for such ionic conditions existing also in vivo.

\section{DISCUSSION}

We have shown here that a phosphorylated form of $\mathrm{CaM}$ is found in conventional preparations of $\mathrm{CaM}$ by using two-dimensional gel electrophoresis with a modified $\mathrm{pH}$ gradient to resolve very acidic proteins. CaM was identified by its heat resistance and retention by an anionexchange resin, by its isoelectric point, and by its molecular weight. Additionally, $\mathrm{Ca}^{2+}$ caused an increase in the electrophoretic mobility of the molecule and its amino acid composition, and, in particular, the presence of TML gave a further criterion of identification of this protein as CaM. $\mathrm{PCaM}$, which was present in the standard preparation of CaM from brain, had the same electrophoretic mobility as $\mathrm{Ca}^{2+} \mathrm{CaM}$ and was partially

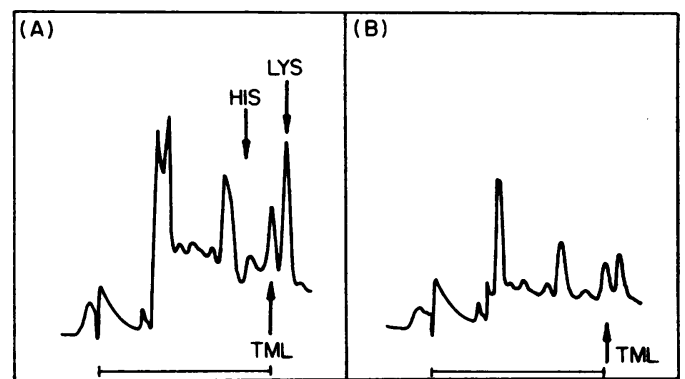

FIG. 4. Amino acid analysis for the TML content of the two CaM variants after electroelution and total acidic hydrolysis. (A) Acidic variant. (B) Main CaM variant. 
converted into $\mathrm{CaM}$ after elution from the gel and reelectrophoresis. The observation of the relative amount of the acidic variant versus the main CaM spot shows that PCaM is unstable in conventional extracts from brain. After a relatively short preparation procedure as shown in Fig. 1A, the acidic variant may be estimated as only a small percentage of the total amount of $\mathrm{CaM}$. On the other hand, it represents about $40 \%$ of the total of the two variants in Fig. 1B when the extraction was done in phosphate and sodium fluoride buffer. The amount of the acidic variant is slightly less in Tris buffer (Fig. 2). This lability of PCaM makes it difficult to set up an experiment to test the role of the purified acidic variant on the activation of another enzymatic system. The acidic variant might be itself an intermediate from an enzymatic reaction involving CaM. It could also correspond to a major form of $\mathrm{CaM}$ in the quiescent cell with a $\mathrm{Ca}^{2+}$ gradient of $10^{6}$ across the membrane. In this case, the $10^{6}$ affinity constant of $\mathrm{CaM}$ for $\mathrm{Ca}^{2+}$ would give very few $\mathrm{CaM}$ molecules in the $\mathrm{Ca}^{2+}$. bound form which may correspond to PCaM. Indeed, in the case of PhK, Cohen (10) discusses a $\delta$ subunit in $\mathrm{PhK}$ which is insensitive to $\mathrm{Ca}^{2+}$. We do not know whether his $\delta$ and $\delta^{\prime}$ terminology corresponds with ours.

A shift in the electrophoretic mobility of CaM in the presence of $\mathrm{Ca}^{2+}$ has been widely used to characterize CaM (23). The removal of $\mathrm{Ca}^{2+}$ by EGTA caused a lower electrophoretic mobility for CaM but did not affect the mobility of PCaM. After total acidic hydrolysis, $\mathrm{CaM}$ and PCaM exhibited the same amino acid composition with the presence, in both of them, of TML. However, PCaM exclusively incorporated ${ }^{32} \mathrm{P}$ when whole brain was incubated with $\mathrm{H}_{3}{ }^{32} \mathrm{PO}_{4}$. After partial acid hydrolysis, phosphoserine was identified as the sole phosphoamino acid. We have also shown that $\mathrm{CaM}$ can be phosphorylated either as the $\delta$ subunit of PhK by autophosphorylation of the enzyme or as exogenous CaM added to a crude extract of $\mathrm{PhK}$.

$\mathrm{PCaM}$ is $1 \mathrm{pH}$ unit more acidic than CaM, having a pI of $3.0 \pm 0.2$. This $\mathrm{pI}$ for PCaM seems very acidic. However, as an example, phosphorylated forms of two proteins from the $80 \mathrm{~S}$ rat liver ribosome with a pI below 2.0 have recently been described (25). After a six-step purification procedure, Watterson et al. (33) found by chemical analysis less than $1 \mathrm{M}$ of phosphorus per CaM polypeptide, although several earlier reports described CaM as a phosphoprotein $(2,8$, 34). As we have shown here, PCaM is labile and can be easily converted to $\mathrm{CaM}$ if precautions are not taken to minimize dephosphorylation. Furthermore, $\mathrm{PCaM}$ is only a minor component of conventional preparations of $\mathrm{CaM}$, but its presence can be conclusively demonstrated in

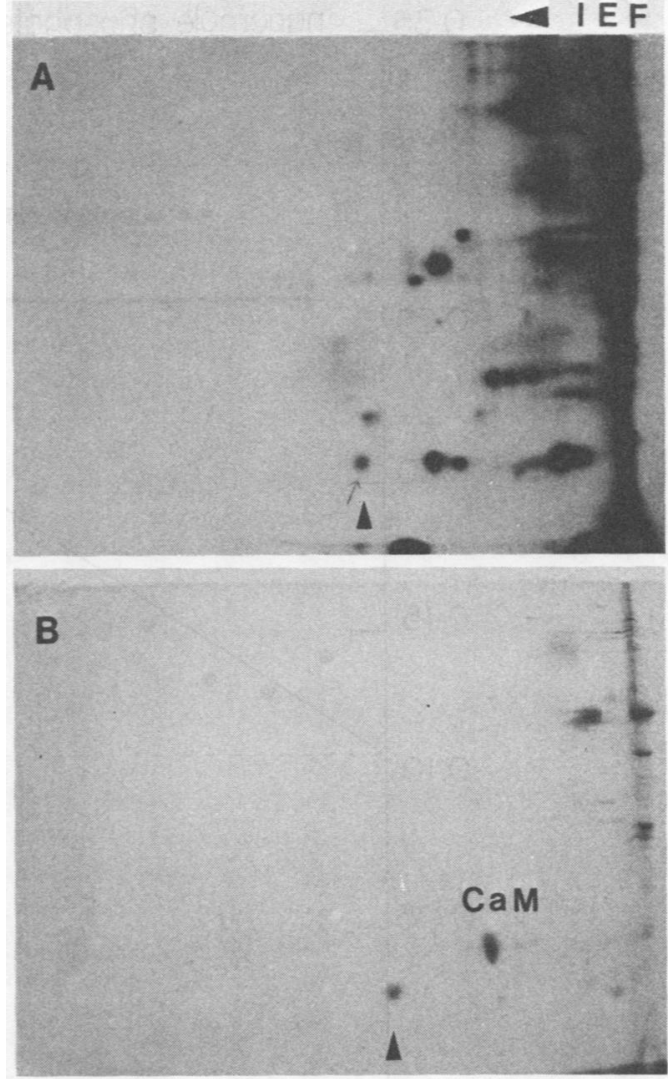

FIG. 5. Incorporation of ${ }^{32} \mathrm{P}$ into the acidic $\mathrm{CaM}$ variant. Whole brain slices were incubated with $\mathrm{H}_{3}{ }^{32} \mathrm{PO}_{4}$ and submitted to urea extraction in Tris-ureaEGTA buffer, and the extracts were analyzed by twodimensional PAGE. (A) Autoradiogram. Only the acidic spot of $\mathrm{CaM}$ is labeled (arrow). (B) Coomassie blue staining of the gel. The arrow shows the position of the acidic CaM variant $\left(\delta^{\prime}\right)$.

whole brain extracts containing phosphatase inhibitors.

What is the cellular function of PCaM? As we have shown, there was no observable change in the electrophoretic mobility of $\mathrm{PCaM}$ in the presence or absence of $\mathrm{Ca}^{2+}$, suggesting that phosphorylation of $\mathrm{CaM}$ may suppress its interaction with $\mathrm{Ca}^{2+}$. Similarly, it has been shown that methylation of $\mathrm{CaM}$ is also followed by an insensitivity to $\mathrm{Ca}^{2+}(13)$. Some $\mathrm{Ca}^{2+}$-independent properties of $\mathrm{CaM}$ have already been reported as, for example, the $\mathrm{Ca}^{2+}$-independent stimulation of Bordetella pertussis adenylate cyclase by CaM (15). Thus, covalent modification of $\mathrm{CaM}$ by phosphorylation may be a mechanism that regulates $\mathrm{Ca}^{2+}$-independent physiological functions of $\mathrm{CaM}$. The $\mathrm{Ca}^{2+}$-independent association of $\mathrm{CaM}$ with $\mathrm{PhK}$, as the $\delta$ subunit of 


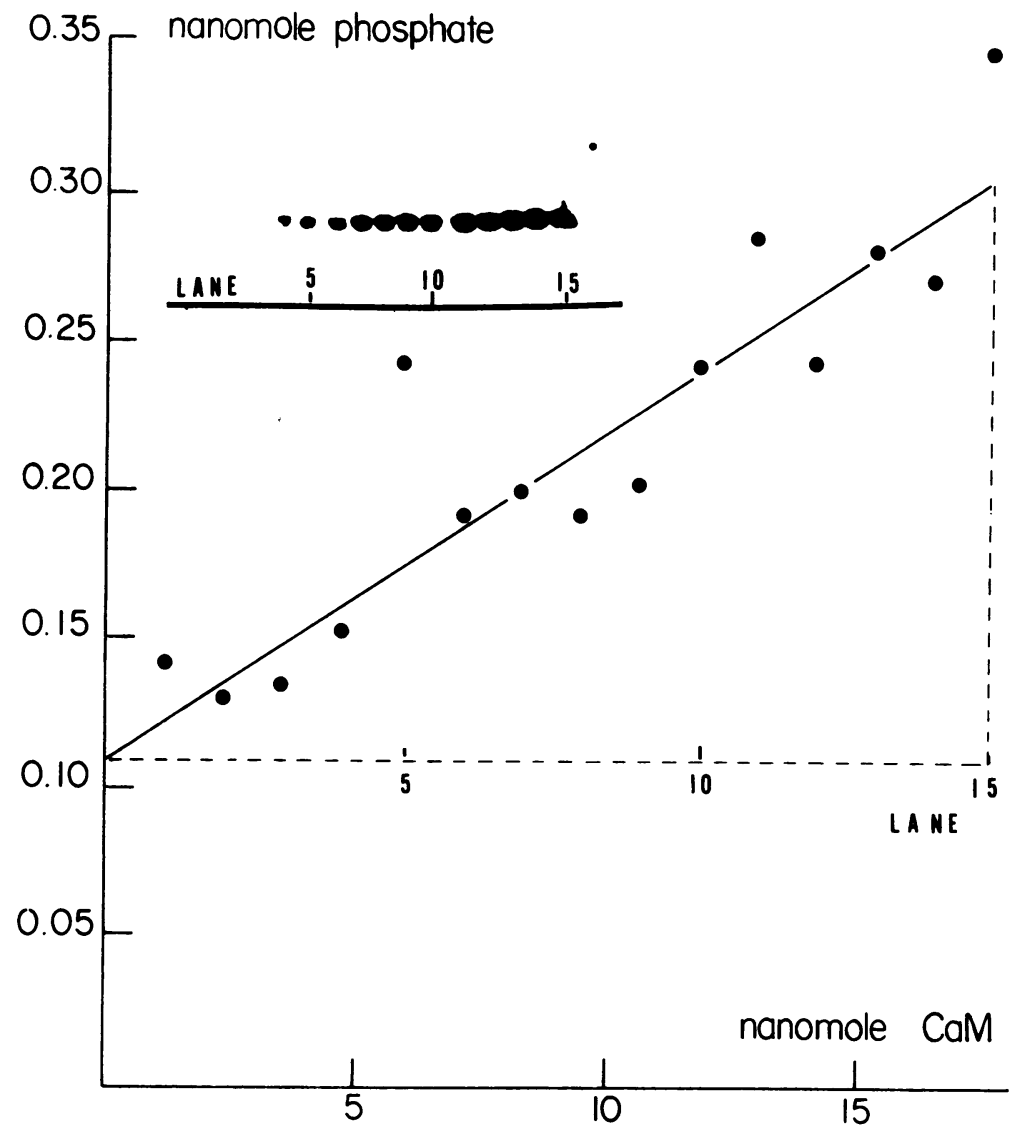

FIG. 6. Phosphorylation of CaM by PhK. The CaM preparation shown in Fig. 1A was added in increasing quantities to a crude preparation of PhK. Quantification of the radioactivity was achieved by liquid scintillation counting. The slope of the line gives $0.10 \mathrm{nmol}$ of phosphate from $\left[\gamma^{32} \mathrm{P}\right] \mathrm{ATP}$ transferred to $10 \mathrm{nmol}$ of CaM. The initial labeling, without CaM added, corresponds to the autophosphorylation of enzyme-bound CaM as its $\delta$ subunit. Inset, autoradiogram of the gel. Each experimental point of the line corresponds to the CaM band in each lane of the autoradiogram.

this enzyme, constitutes another example of a $\mathrm{Ca}^{2+}$-independent interaction of $\mathrm{CaM}(12,23)$. The existence of PCaM may lead also to the elucidation of the regulation of some dephosphorylation processes such as that mediated by brain calcineurin, a two-chain enzyme known to be a CaM-dependent phosphatase $(32,35)$. Furthermore, as discussed by Cohen (10), CaM is closely interrelated with cAMP in the hormonal or neuronal control of cellular activity leading to physiological events. This control occurs mainly by protein phosphorylation, and phosphorylation of CaM may be an additional level of control.

The fact, as we have demonstrated, that the $\delta$ subunit of PhK can be phosphorylated makes this region of the molecule very important for the understanding of its enzymatic activity. Although the phosphorylating activity of PhK was among the first known processes of phosphor- ylation (10), the mechanism of its action is not elucidated (21). The $\delta$ subunit confers to the enzyme its sensitivity to $\mathrm{Ca}^{2+}(11)$; its phosphorylation may result in an activation of the whole enzyme. As has been shown, the other subunits of PhK can also be phosphorylated by a cAMPdependent kinase $(10,19)$. The phosphorylation of the $\delta$ subunit, however, cannot be due to a cAMP-dependent mechanism, since the characteristic sequence for a cAMP-dependent phosphorylation by the cAMP-dependent kinases is not found in CaM (23). Furthermore, dogfish skeletal muscle $\mathrm{PhK}$ is not regulated by a cAMP phosphorylation-dephosphorylation mechanism, as is the case with the mammalian enzyme (30). The activity of the enzyme from this early vertebrate relies only upon a $\mathrm{Ca}^{2+}$ CaM-dependent activation, and despite that fact, it shows a substrate activity toward rabbit phosphorylase close to that on dogfish phos- 
phorylase. Perhaps phosphorylation of $\mathrm{CaM}$ in dogfish PhK may be a mechanism by which the enzyme regulates its interaction with $\mathrm{Ca}^{2+}$.

In addition to its possible involvement in the regulation of the PhK enzymatic activation, PCaM may also be involved in a number of membrane phenomena in which fluxes of $\mathrm{Ca}^{2+}$ play a vital role for any change in cellular metabolism (23). In the cardiac sarcoplasmic reticulum, the membrane-bound $\mathrm{Ca}^{2+}$-dependent kinase is very similar to and interchangeable with $\mathrm{PhK}$ and requires $\mathrm{CaM}$. The $\alpha$ and $\beta$ subunits of $\mathrm{PhK}$ have been shown to associate with the sarcoplasmic reticulum, and the membrane-bound kinase could represent a specific particulate form of $\mathrm{PhK}$ (23). A variety of tissues containing membrane-bound $\mathrm{CaM}$-dependent protein kinase phosphorylate membrane proteins whose identity and function are yet unknown (10). The existence of PCaM is crucial for the understanding of these membranous systems. The membrane location of $\mathrm{CaM}$ as part of a multimolecular complex has to be considered also in the erythrocyte membrane in which $\mathrm{CaM}$ has been shown to interact with spectrin (31) and in which proteins such as goblin are phosphorylated by a CaM-activated protein kinase (1). Similarly, since spectrin has been shown to be associated with the plasma membrane and to bind $\mathrm{CaM}$ also in many nonerythroid cells (for review see reference 24), then PCaM may be an additional way for cells to regulate membranecytoskeletal interactions.

Among the numerous physiological implications thus far described for $\mathrm{CaM}$, the evidence presented here for its phosphorylation opens a new way in the study of the already available experimental models involving this small, ubiquitous protein.

\section{ACKNOWLEDGMENTS}

We thank B. L. Granger for his comments on the manuscript.

This work was supported by grants from the National Institutes of Health, the National Science Foundation, and the Muscular Dystrophy Association of America, Y.D.P. is Charge de Recherches at the C.N.R.S., Paris, France. E.L. is a recipient of a Research Career Development Award from the National Institutes of Health.

\section{LITERATURE CITED}

1. Alper, S. L., H. C. Palfrey, S. A. Deriemer, and P. Greengard. 1980. Hormonal control of protein phosphorylation in turkey erythrocytes. Phosphorylation by cAMP-dependent and $\mathrm{Ca}^{++}$dependent protein kinases of distinct sites in goblin, a high molecular weight protein of the plasma membrane. J. Biol. Chem. 255:11029-11039.

2. Brooks, J. C., and F. L. Siegel. 1973. Purification of a $\mathrm{Ca}^{++}$-binding phosphoprotein from beef adrenal medulla. J. Biol. Chem. 248:4189-4193.

3. Burgess, W. H., D. K. Jemiolo, and R. H. Kretsinger. 1980. Interaction of calcium and calmodulin in the presence of sodium dodecyl sulfate. Biochim. Biophys. Acta
623:257-270.

4. Burgoyne, R. D. 1981 . The loss of muscarinic acetylcholine receptors in synaptic membranes under phosphorylating conditions is dependent on calmodulin. FEBS Lett. 127:144-148.

5. Cheung, W. Y. 1970. Cyclic 3',5'-nucleotide phosphodiesterase. Demonstration of an activator. Biochem. Biophys. Res. Commun. 38:533-538.

6. Cheung, W. Y. 1971. Cyclic 3',5'-nucleotide phosphodiesterase. Evidence for and properties of a protein activator. J. Biol. Chem. 246:2859-2869.

7. Cheung, W. Y. 1982. Calmodulin. Sci. Am. 246:62-81.

8. Cheung, W. Y., L. S. Bradham, T. J. Lynch, Y. M. Lin, and E. A. Tallant. 1975. Protein activator of cyclic 3',5'nucleotide phosphodiesterase of bovine or rat brain also activates its adenylate cyclase. Biochem. Biophys. Res. Commun. 66:1055-1062.

9. Cohen, P. 1973. The subunit structure of rabbit skeletal muscle phosphorylase kinase, and the molecular basis of its activation reactions. Eur. J. Biochem. 34:1-14.

10. Cohen, P. 1982. The role of protein phosphorylation in neuronal and hormonal control cellular activity. Nature (London) 296:613-620.

11. Cohen, P., A. Burchell, J. G. Foulkes, P. T. W. Cohen, T. C. Vanaman, and A. C. Nairn. 1978. Identification of the $\mathrm{Ca}^{++}$-dependent modulator protein as the fourth subunit of rabbit skeletal muscle phosphorylase kinase. FEBS Lett. 92:287-293.

12. De Martino, G. N., and D. K. Blumenthal. 1982. Identification and partial purification of a factor that stimulates calcium-dependent proteases. Biochemistry 21:42974303.

13. Gagnon, C., S. Kelly, v. Manganiello, M. Vaughan, C. Odya, W. Strittmatter, A. Hofiman, and F. Hirata. 1981. Modification of calmodulin function by enzymatic carboxyl methylation. Nature (London) 291:515-516.

14. Glenney, J. R., A. Bretscher, and K. Weber. 1980. Calcium control of the intestinal microvillus cytoskeleton: its implications for the regulation of microfilament organization. Proc. Natl. Acad. Sci. U.S.A. 77:6458-6462.

15. Greenlee, D. V., T. J. Andreasen, and D. R. Storm. 1982. Calcium-independent stimulation of Bordetella Pertussis adenylate cyclase by calmodulin. Biochemistry 21:27592764.

16. Henderson, L. E., S. Oroszlan, and W. Konigsberg. 1979. A micromethod for complete removal of dodecyl sulfate from proteins by ion-pair extraction. Anal. Biochem. 93:153-157.

17. Jesse-Chan, K. F., and D. J. Graves. 1982. Isolation and physicochemical properties of active complexes of rabbit muscle phosphorylase kinase. J. Biol. Chem. 257:59395947.

18. Jesse-Chan, K. F., and D. J. Graves. 1982. Rabbit skeletal muscle phosphorylase kinase. Interactions between subunits and influence of $\mathrm{CaM}$ on different complexes. J. Biol. Chem. 257:5956-5961.

19. Jesse-Chan, K. F., M. A. Hurst, and D. J. Graves. 1982. Phosphorylase kinase specificity. A comparative study with cAMP dependent protein kinase on synthetic peptides and peptide analogs of glycogen synthase and phosphorylase. J. Biol. Chem. 257:3655-3659.

20. Kakiuchi, S., and R. Yamasaki. 1970. Calcium dependent phosphodiesterase activity and its activating factor (PAF) from brain. Biochem. Biophys. Res. Commun. 41:11041110.

21. Kilimann, M. W., and L. M. G. Heilmeyer. 1982. Multiple activities on phorphorylase kinase 2 . Different specificities toward the protein substrates phosphorylase $b$, troponin, and phosphorylase kinase. Biochemistry 21:17351739.

22. Klagsburn, M., and A. V. Furano. 1975. Methylated amino acids in the proteins of bacterial and mammalian cells. Arch. Biochem. Biophys. 169:529-539.

23. Klee, C. B., T. H. Crouch, and P. G. Richman. 1980. Calmodulin. Annu. Rev. Biochem. 49:489-515. 
24. Lazarides, E., and W. J. Nelson. 1980. Expression of spectrin in nonerythroid cells. Cell 31:505-508.

25. MacConnell, W. P., and N. O. Kaplan. 1982. The activity of the acidic phosphoproteins from the $80 \mathrm{~S}$ rat liver ribosome. J. Biol. Chem. 257:5359-5366.

26. Oakley, B. R., D. R. Kirsch, and N. R. Morris. 1980. A simplified ultrasensitive silver stain for detecting proteins in polyacrylamide gels. Anal. Biochem. 105:361-363.

27. O'Connor, C. M., D. L. Gard, and E. Lazarides. 1981. Phosphorylation of intermediate filament proteins by cAMP-dependent protein kinases. Cell 23:135-143.

28. O'Farrell, P. H. 1975. High resolution two-dimensional electrophoresis of proteins. J. Biol. Chem. 250:4007-4021.

29. Paik, W. K., and S. Kim. 1980. Protein methylation. In A Meister (ed.), Biochemistry series. John Wiley \& Sons, Inc., New York.

30. Pocinwong, S., H. Blum, D. Malencik, and E. H. Fischer. 1981. Phosphorylase kinase from dogfish skeletal muscle. Purification and properties. Biochemistry 20:7219-7226.
31. Sobue, K., Y. Muramoto, M. Fujita, and S. Kakiuchi. 1981. CaM binding protein of erythrocyte cytoskeleton. Biochem. Biophys. Res. Commun. 100:1063-1070.

32. Stewart, A. A., T. S. Ingebritsen, A. Manalan, C. B. Klee, and P. Cohen. 1982. Discovery of $\mathrm{a} \mathrm{Ca}^{2+}$ and calmodulindependent protein phosphatase. Probable identity with calcineurin (CaM-BP80). FEBS Lett. 137:80-84.

33. Watterson, D. M., W. G. Harrelson, P. M. Keller, F. Shariff, and T. C. Vanaman. 1976. Structural similarities between the $\mathrm{Ca}^{2+}$-dependent regulatory proteins of $3^{\prime}: 5^{\prime}$ cyclic nucleotide phosphodiesterase and actomyosin ATPase. J. Biol. Chem. 251:4501-4513.

34. Wolf, D. J., and C. O. Brostrom. 1974. $\mathrm{Ca}^{++}$-binding phosphoprotein from pig brain: identification as a $\mathrm{Ca}^{++}$. dependent regulator of brain cyclic nucleotide phosphodiesterase. Arch. Biochem. Biophys. 163:349-358.

35. Yang, S. D., E. A. Tallant, and W. Y. Cheung. 1982. Calcineurin is a CaM-dependent protein phosphatase. Biochem. Biophys. Res. Commun. 106:1419-1425. 